\title{
FLUORESCENCE AND ABSORPTION SPECTROSCOPY - FAST METHODS FOR DETERMINING THE CONTENT OF ANTIOXIDANTS AND AGE OF BULGARIAN WINES
}

\author{
Krastena Nikolova ${ }^{1}$, Stefka Minkova ${ }^{1}$, Tinko Eftimov², Stefan Krustev ${ }^{1}$ \\ ${ }^{1}$ Department of Physics and Biophysics, Medical University of Varna, Bulgaria \\ ${ }^{2}$ Département d'Informatique et d'Ingénierie, Université du Québec en Outaouais, \\ Gatienau, Québec, Canada
}

\begin{abstract}
This paper describes a study of usefulness of some optical methods to determine the grape variety and the age of Bulgarian wines from Southern Bulgaria. We have tested two optical methods measuring the optical density and fluorescence spectra in the UV region. The data for color intensity, hue and color composition have been obtained by using absorbance spectra. A correlation between fluorescence intensity and antioxidant activity of the wine can be found, which is very important for human health and hygiene of eating. All of the obtained experimental results suggest that two optical methods could be useful for quality estimation of wine age and quality determination of some fluorescence components in wine with antioxidant properties.
\end{abstract}

Keywords: fluorescence, optical density, wine quality, color parameters, antioxidant activity, hygiene of eating

\section{INTRODUCTION}

Wine contains a wide range of naturally fluorescent compounds most of which are polyphenols. These compounds are important in food hygiene due to their bactericidal effect. Many epidemiological studies in humans show a positive correlation between the incidence of chronic diseases and oxidative stress in pathogenesis (1). According to Manach et al. (2) red wine possesses high concentration of numerous bioactive dietary polyphenols. It is a fermented alcoholic beverage containing various compounds of

Address for correspondence:

Krastena Nikolova

Department of Physics and Biophysics

Medical University of Varna

55 Marin Drinov St

9002 Varna

e-mail:kr.nikolova@abv.bg

Received: May 2, 2017

Accepted: June 15, 2017 different type, such as polyphenols, flavonoids, anthocyanins, phenolic acids, stilbenes and many other polyphenols (3). It is essentially a solution of 10$15 \%$ ethanol in water with $\mathrm{pH}$ usually between 3.2 and 4 . The composition is highly dependent on factors such as grape variety, maturity at harvest, soil type, climate conditions, wine making processes so that each type of wine is different and has its own characteristics.

Fluorescence spectroscopy is an instrumental technique whose theory and methodology has been widely exploited for studies of molecular structure of food products and beverages (4). Its main advantages are sensitivity, easy use, speed of analysis and its non-destructive character, without using chemical reagents. Many authors have characterized wine from different grapes and geographical origins.

For example, Dufour et al. investigated both excitation and emission spectra for French and German wine classification (5), and Sadecka et al. reported the classification of brandies and wine distillates 
Krastena Nikolova, Stefka Minkova, Tinko Eftimov et al.

using total luminescence and synchronous fluorescence spectra (6). Azcarate et al., in 2015, discriminated Argentinian white wines varieties by using fluorescence spectroscopy (7).

The aim of our research is to reveal the potential of fluorescence spectroscopy and to show that the fluorescence spectra can be used for a better assessment of different types of Bulgarian wines. In this paper it is demonstrated that the optical parameters can be used for estimation of age of wines and qualitative determination of fluorescent compounds, which have positive influence over human health.

\section{MATERIALS AND METHODS \\ Samples}

13 different types of wine have been investigated. The samples were taken from a wine cellar or a supermarket. The majority of wines were from the southern part of Bulgaria (from the regions of Starosel, Yambol, Brestovica, Parvomai), 2014 or 2015 vintage. More information about the investigated samples is given in Table 1 .

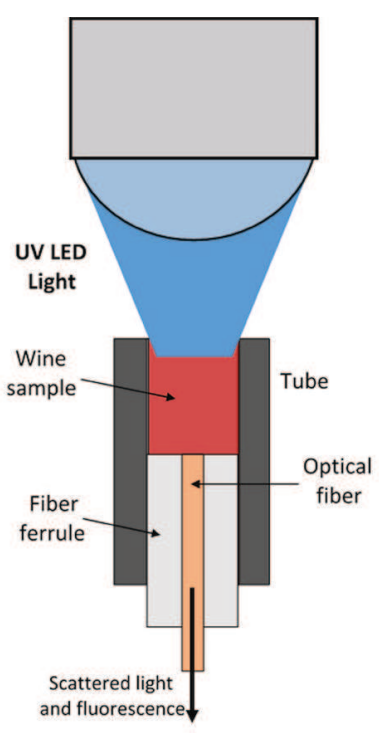

Fig. 1. Experimental set-up

A drop of wine samples was placed in a special place constructed for measuring of red wine without dilution. The scheme is presented on Figure 1.

Table 1. Specifications of the investigated samples

\begin{tabular}{lcccc}
\hline № & Grape variety & Place & Geographic origin & Year \\
1 & Merlot+Marcelin & Wine cellar & Parvomai & 2014 \\
2 & Merlot & Wine cellar & Parvomai & 2014 \\
3 & Merlot reserve & Supermarket & Yambol & 2014 \\
4 & Merlot & Supermarket & Yambol & 2014 \\
5 & Merlot & Wine cellar & Starosel & 2015 \\
6 & Syrah & Wine cellar & Parvomai & 2014 \\
7 & Rubin & Wine cellar & Parvomai & 2014 \\
8 & Red wine & Supermarket & Starosel & 2015 \\
9 & Red wine & Supermarket & Brestovica & 2015 \\
10 & Sauvignon Blanc & Wine cellar & Parvomai & 2014 \\
11 & Chardonnay & Supermarket & Yambol & 2015 \\
12 & Rose & Supermarket & Yambol & 2015 \\
13 & White wine & Supermarket & Starosel & 2015 \\
\hline
\end{tabular}

\section{Used Optical Methods}

\section{Fluorescence Spectra Measurements}

The sources used to measure the fluorescence spectra are $245 \mathrm{~nm}, 265 \mathrm{~nm}, 275 \mathrm{~nm}$ and $290 \mathrm{~nm}$ light-emitting diodes (LEDs). A fiber optic spectrometer (AvaSpec-2038, Avantes) with sensitivity in the $(200-1100) \mathrm{nm}$ range and a resolution of about $8 \mathrm{~nm}$ was used to measure the fluorescence spectra.

\section{Absorption Measurements}

Determining the transmission and absorption characteristics of the wines was performed using a spectrophotometer Thermo Scientific Helios Omega UV-VIS in the visible region with the cuvette with a thickness of $1 \mathrm{~mm}$ and capacity of $0.2 \mathrm{ml}$.

The analysis in winemaking requires optical density (D) measurements at $420 \mathrm{~nm}$ and $520 \mathrm{~nm}$, with an additional measurement at $620 \mathrm{~nm}$ to in- 
clude the blue component in young red wines. These measurements are used to calculate the values - color intensity, color composition, the brilliance of red wines - used to describe wine color (8) and estimate age of the samples.

$\diamond$ Color intensity (CI) represents the amount of color. It varies a great deal from one wine and grape variety to another (0.3-1.9) (9)

$\Leftrightarrow C I=D_{420}+D_{520}+D_{620}$

$\diamond$ Color composition, i.e. the contribution (expressed as a percentage) of each of the three components in the overall color (9):

$$
\begin{aligned}
& \diamond D_{420}(\%)=\frac{D_{420}}{C I} \cdot 100 \\
& D_{520}(\%)=\frac{D_{520}}{C I} \cdot 100 \\
& D_{520}(\%)=\frac{D_{520}}{r t} \cdot 100 \\
& D_{620}(\%)=\frac{D_{620}}{C I} \cdot 100
\end{aligned}
$$

$\diamond$ The hue (color shade) indicates the development of a color towards orange (9).

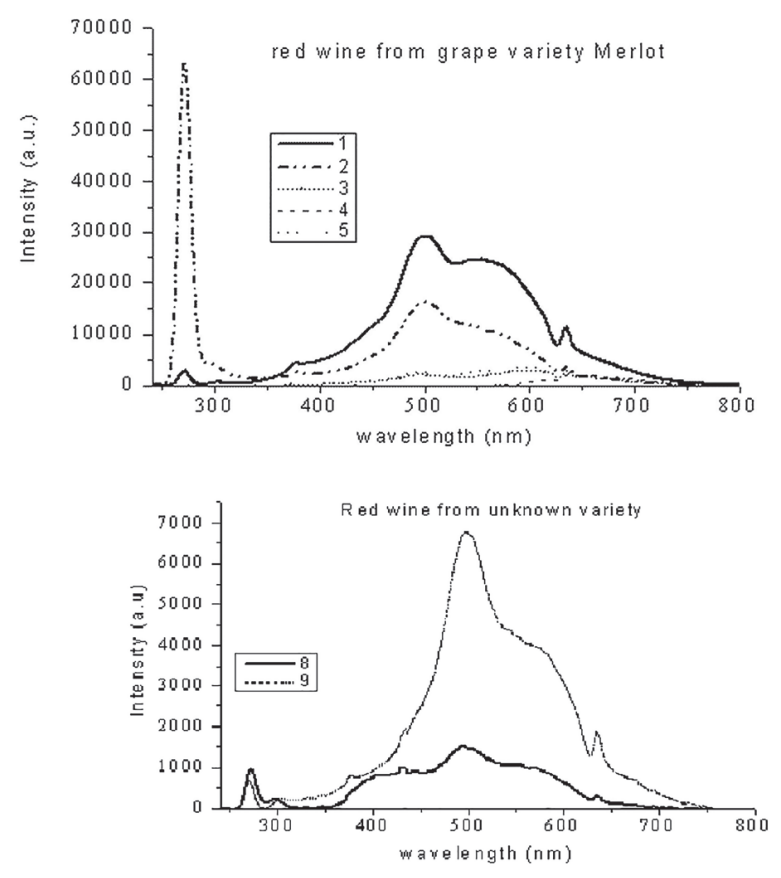

$$
T=\frac{D_{420}}{D_{520}} T=\frac{D_{420}}{D_{520}}
$$

\section{Statistical Methods}

The mathematical processing of the data from absorption and transmission spectra in the visible region and the calculated from them color parameters for wine was done by hierarchical cluster analysis with a measure of similarity of Euclidean distance $(10,11)$. The data were standardized preliminary in order to avoid the influence of different dimensions. The results from the cluster analysis are presented by a dendrogram. The SPSS software was used for clusterization of the wines.

\section{RESULTS AND DISCUSSION}

The emission fluorescence spectra of wine were obtained for the excitation signal wavelength as follows $245 \mathrm{~nm}, 265 \mathrm{~nm}, 275 \mathrm{~nm}, 295 \mathrm{~nm}$. The emission fluorescence spectra are presented for excitation wavelength $265 \mathrm{~nm}$ on Figure 2. This wavelength is chosen, because for it the ratio between intensity of emission and intensity of excitation is high and fluorescence spectra are distinct.

It is evident that the white and rose wines have one broad band with a similar form, whose intensi-
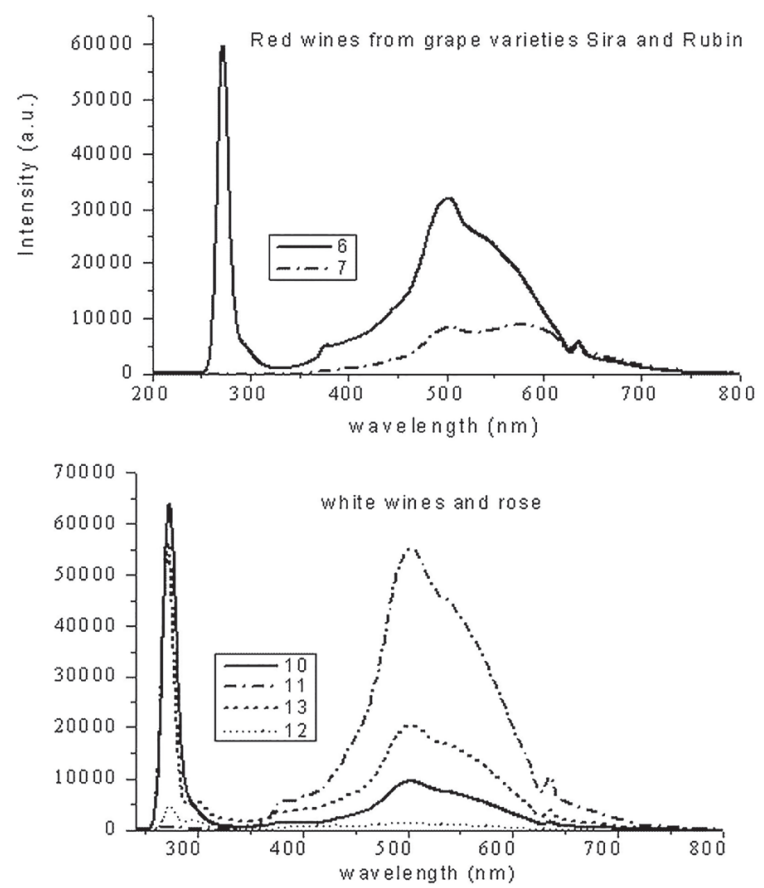

Fig. 2. Fluorescence spectra of wine from Southern Bulgaria for excitation wavelength of $265 \mathrm{~nm}$ 
Krastena Nikolova, Stefka Minkova, Tinko Eftimov et al.

ty depends on the grape variety. Red wines from different kinds of grapes possess more than one fluorescence peak and their intensity of emission depends of numerous fluorescent components. Excitation with higher energy radiation at wavelengths between 245 $\mathrm{nm}$ and $295 \mathrm{~nm}$ fluorescence emission was observed in the $340 \mathrm{~nm}$ to $540 \mathrm{~nm}$ range. Similar results have been reported by Rado-Rodriguez et al. (12).

Wine contains a wide range of naturally occurring fluorescent compounds such as phenolic acids (gallic, vanillic, caffeic, ferulic acid), flavonoids, vitamins and amino acids (13-15). For this reason the fluorescence characteristics of wine are expected to be quite complex due to overlapping of emission from numerous components. Quantity analysis of fluorescence components in wine was not conducted, but the qualitative comparison of the experimental results with well-known fluorescent properties of wine was performed.

Several fluorescence substances could be distinguished in the wine samples. When the sample was excited at $245 \mathrm{~nm}$, it showed emission peak in the region $429 \mathrm{~nm}-440 \mathrm{~nm}$. The main phenolic acids such as caffeic, gallic and ferulic acids contribute to this fluorescence peak. Similar results were reported from Rodrigues and Bravo (16-17).

White wines and three of the red wines possessed a maximum of emission between $350 \mathrm{~nm}$ and $415 \mathrm{~nm}$, when they were excited at wavelength 295 $\mathrm{nm}$. Similar results are shown from Lakowicz (18).

Fluorescence spectroscopy can be used for distinguishing of some vitamins. According to Krasnikov and Timoshkin (19-21) fluorescence maxima of vitamins are as follows: Vitamin A (retinol) $-\lambda_{\text {em }}=512-515 \mathrm{~nm}\left(\lambda_{\text {exc }}=320-400 \mathrm{~nm}\right)$, Vitamin $\mathrm{E}$ (a-tocopherol) $-\lambda_{\text {em }}=392-394 \mathrm{~nm}\left(\lambda_{\text {exc }}=270-310 \mathrm{~nm}\right.$ and 320-340 nm), Vitamin C - 455-458 nm (320-340 and $370-390 \mathrm{~nm}$ ). It was found for the samples under study that with excitation in the $270 \mathrm{~nm}$ to 280 $\mathrm{nm}$ range, fluorescence peaks were observed in the $394 \mathrm{~nm}$ to $410 \mathrm{~nm}$, which could be attributed to vitamin E (20). Therefore, white and rose wines are rich in Vitamin E (a-tocopherol). The most powerful fluorescence peaks of white wines were exhibited by the Chardonnay types, while from the red wines the only sample exhibiting such properties as the Syrah sample was obtained by pumping the samples at $265 \mathrm{~nm}$.
All samples, excluding sample 4, exhibited a peak in the $495 \mathrm{~nm}$ to $503 \mathrm{~nm}$ that can be associated with the presence of riboflavin (Vitamin $\mathrm{B}_{2}$ ). According to Christensen (22), riboflavin has an emission maximum around $510 \mathrm{~nm}$ to $518 \mathrm{~nm}$ at $\lambda_{\mathrm{ex}}=270 \mathrm{~nm}$ or at $\lambda_{\text {ex }}=382 \mathrm{~nm}$. The present study does not comment on the contents of Vitamins A and C, not because these are not present in Bulgarian white and red wines, but because the present studies are in the visible range.

Two more fluorescence peaks were observed:

1. At $\lambda_{\mathrm{ex}}=265 \mathrm{~nm}$ part of the intensely colored red wines (samples from 3 to 5) exhibited a peak of fluorescence emission around $600 \mathrm{~nm}$ to $640 \mathrm{~nm}$. This peak is not identified in literature on fluorescence spectroscopy of wines, but is known as a range of fluorescence of chlorophyll and other pigments of this group. In some samples of red wines, the presence of pigments is caused by the technology or processing of grapes and wine production.

2. At $\lambda_{\text {ex }}=245 \mathrm{~nm}$ all white, rose and part of the red wines exhibited a fluorescence peak in the 482 $\mathrm{nm}$ to $488 \mathrm{~nm}$ range. Similar results are reported from Sadecka et al. (6). The shape and intensity of these intermediate emissions varied from one distillate to another.

The knowledge of fluorescence components in wines is very important, because fluorescence peaks give information about different phenolic classes tannins, phenolic acids, flavonoids, anthocyanins. Recent studies indicate that consumption of small amounts of red wine on a regular basis reduced the risk of coronary heart disease and this can be explained by the antioxidant properties of polyphenolic compounds (23). Also, anthocyanins are linked to the ability to reduce cancer cell proliferation and inhibit tumor formation (24).

The qualitative determination of vitamins in wines is of great importance, because they are essential nutrients for humans to maintain normal activity, play an important role in metabolism, such as reducing the concentrations of homocysteine (25), slowing the progression of diabetic nephropathy, and preventing vascular events (26). It is known that the non-alcoholic component of wine is a protective factor in regard to human health (27-28). 
The white and rose wines are very helpful, because they contain vitamin E. It intercalates itself into lipid membranes of cells and helps halt the peroxidation of lipid molecules. Many authors describe that vitamin $\mathrm{E}$ affects the activation of protein kinase $\mathrm{C}$, protein phosphatase $2 \mathrm{~A}$, and protein kinase $\mathrm{B}$ in mast cells (29-30).

The fluorescence peak in the (400-420) $\mathrm{nm}$ range at excitation wavelengths of (260-275) nm has been connected with flavonoids and polyphenols according to Rodriguez-Delgado et al. (16-17). Flavonoids are an important group of substances because they have antioxidant, anti-allergic and anti-tumor activities (31). Kaur et al. (2016) reported that wine helps to protect blood vessels from rupture or leakage (32). The recommended dietary allowance according to clinical trials is from $500 \mathrm{mg}$ to $2000 \mathrm{mg}$. The therapeutic range varies from $50 \mathrm{mg}$ to $500 \mathrm{mg}$ daily (33). Phenols are also important, because they determine the sensory characteristics of wine and play a key role in food hygiene due to their antibacterial effect (33).

The main characteristics of wine samples, obtained by using the spectra of adsorption, are shown on Figure 3 and 4 . It should be noted that the numbers on the abscissa on Figure 3 and 4 correspond to the numbers of wines given in Table 1 .
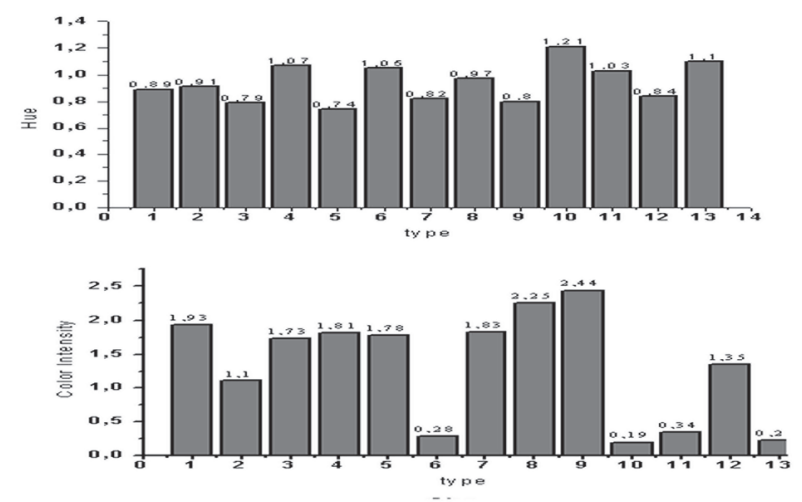

Fig. 3. Color intensity and hue of Bulgarian wines

The hypothesis raised in 2006 (9) is that color intensity depends on the type of grapes. For red wines of the typical for Bulgaria Merlot type the peak intensity varies between 1.7 and 1.9. Only one of the samples showed a lower color intensity around 1.10, which can be attributed to climatic conditions in the region where the grapes were grown. It is character- istic for white wines that their color intensity is at the lower limit of 0.3 . There was no explicitly expressed dependence on the type of grapes, which could be attributed to their high transmission in the visible. In red wines the dependence on the type was strong the Syrah type had color intensity at the lower limit 0.3, while that of Rubin - almost at the upper limit of 1.8. For two of the red wines without indication of the type on the label, a deviation from this dependence was observed. They were characterized by a color intensity above the indicated interval - between 2.3 and 2.4. The latter fact is associated with intensity of the red color and a large absorption in spite of the thin liquid layer. The shade of the color can be a quality characteristic of the age of wine. Wines with values between 0.5 and 0.8 were wines from the harvest of the previous year and this characteristic increases to a maximum of 1.2 to 1.3 with the storage time of the wines. It is seen from Fig. 3 that about $62 \%$ of the number of studied samples were young wines, $31 \%$ were from previous harvests and a sample of white wine, Sauvignon Blanc, belonged to the group of the old wine.

Color composition for the main wavelength 420 $\mathrm{nm}, 520 \mathrm{~nm}$ and $620 \mathrm{~nm}$ is presented on Figure 4 .

The contribution of the component at $520 \mathrm{~nm}$ in the color contents dominated in the samples of rose and red wines excluding two samples - Syrah and Merlot, the difference being minimal and of the order of $1-2 \%$. For white wines the contribution of the component at $420 \mathrm{~nm}$ dominated over the remaining two in the color contents.

Determining the color parameters is essential for the evaluation of wines from known varieties of red grapes obtained by various methods of grape pulp processing in order to increase the extraction of phenolic compounds and polysaccharides (34). For the evaluation of the content of these compounds in red wine from grape variety Mavrud, the method of Glories (35) and the method of Sudro (36) were used.

On the other hand, content of color of European wine is used for:

$\diamond$ Determining the characteristics of the normal development of bottle-aged red wines. It is known that breakdown of anthocyanins and tannins may lead to a loss of color (9). 

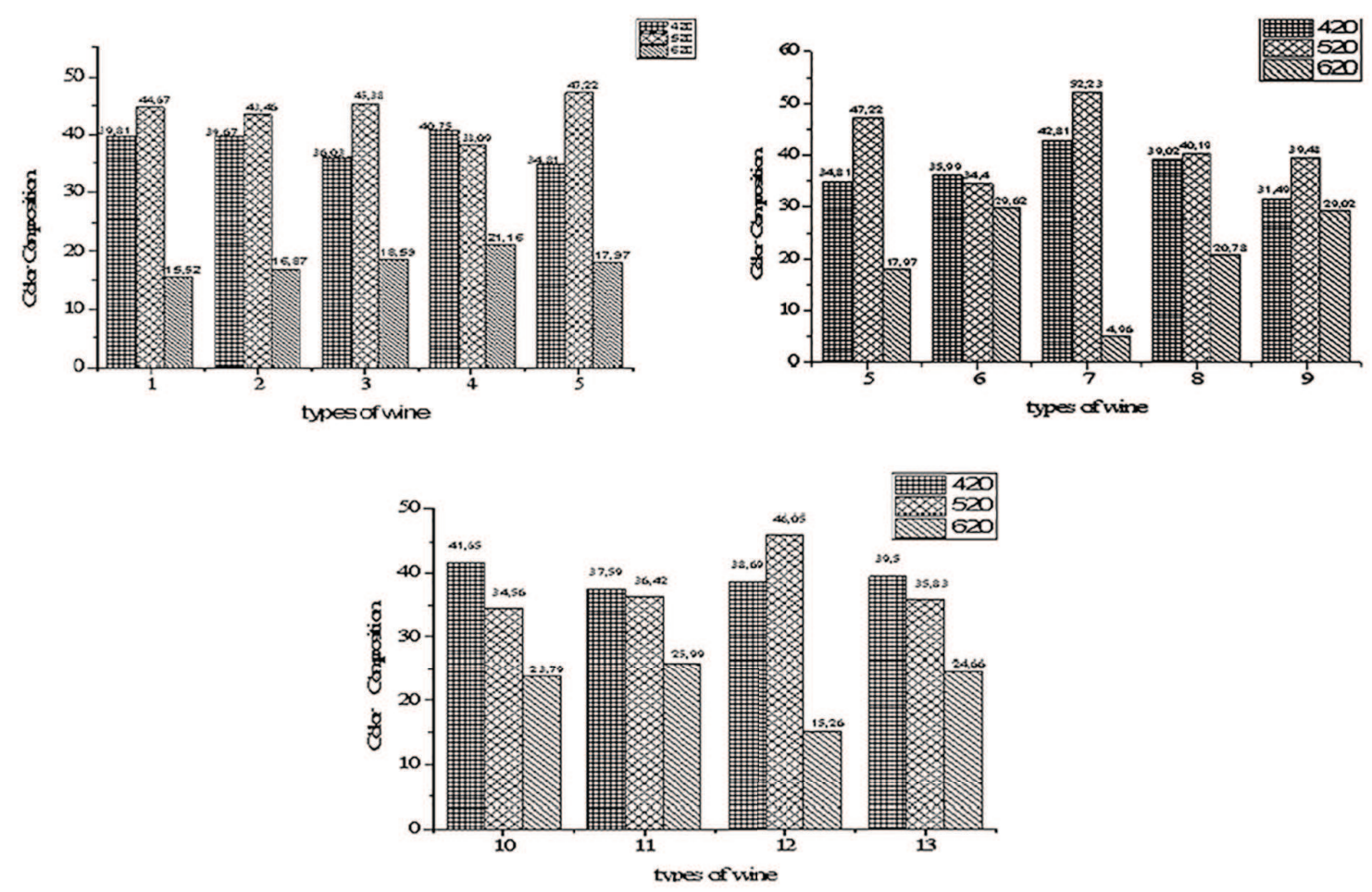

Fig. 4. Color composition for Bulgarian wine

$\diamond$ Evaluation of oxidation of phenolic compounds of white wine (9).

$\diamond$ Differentiation of sweet white and dry white wines. It is known that the dry white wine has brown hue, due to modification in tannins.

By using the literature results it can be concluded that the color parameters are related to the content and the quality of wine.

The grouping of the samples in clusters is presented with the dendrogram on Figure 5 and the values of the distances between groups is shown in Table 2 .

Two clusters were formed. The first group included all samples made from grapes with a dominating Merlot type as well as the rose sample. The second cluster included three subclusters - one containing all white wines (10, 11 and 13), and two other unifying red wine with the non-indicated on the label type together with Syrah, Rubin and one of the Merlots which was not classified correctly. The latter fact was confirmed by fluorescence spectroscopy, which exhibited a considerably weaker emission intensity in a different form of the peak for sample 4. Hence, the dominating type of grapes in the indi-
Table 2. Combinations of clusters and distances between

\begin{tabular}{|lc|c|c|}
\hline \multicolumn{4}{c}{ groups } \\
\hline \multirow{2}{*}{ Stage } & Cluster Combined & Coefficients \\
\hline 1 & Cluster 1 & Cluster 2 & 3.740 \\
2 & 1 & 12 & 5.266 \\
3 & 2 & 3 & 5.812 \\
4 & 11 & 13 & 7.376 \\
5 & 1 & 5 & 7.811 \\
6 & 4 & 8 & 15.958 \\
7 & 10 & 11 & 27.518 \\
8 & 1 & 2 & 38.838 \\
9 & 4 & 10 & 53.803 \\
10 & 6 & 9 & 96.944 \\
11 & 4 & 6 & 171.150 \\
12 & 1 & 4 & 491.954 \\
\hline \hline
\end{tabular}

cated wine was not Merlot. The dominating type of grapes in it could coincide with the dominating type in sample 8.

The shortest Euclidian distance existed between samples 1 and 12. This can be explained with the different technology of making rose wine, but the wine can be made from grapes form one of the types of sample 1 - Merlot and Marceline. The most dis- 
Fluorescence and Absorption Spectroscopy - Fast Methods for Determining of Content of Antioxidants and Age of Bulgarian Wines

tant were samples 1 and 4 , and 1 and 7 with distances correspondingly 171.15 and 491.95 . The former fact is associated with the wrong classification of sample 4 due to differences in the optical parameters, characteristic for the indicated sort, while the second can be associated with the too dense color of the Rubin sample.

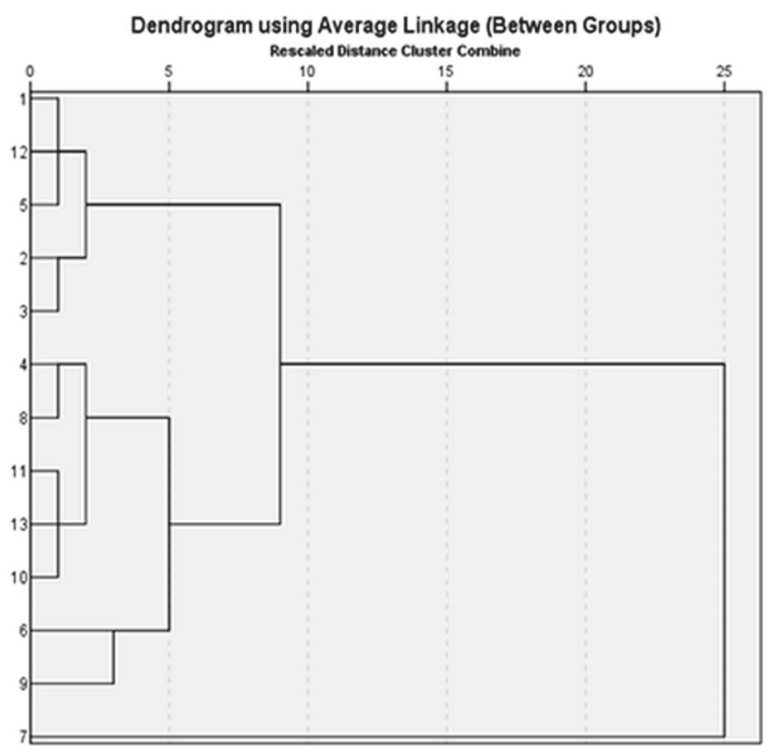

Fig. 5. Dendrogram based on the hierarchical cluster analysis

The percentage distribution of the wine in the distinct subcluster is presented in Table 3.

Table 3. Distribution of wine samples in clusters

\begin{tabular}{lccc} 
№ & $\begin{array}{c}\text { Samples in } \\
\text { clusters }\end{array}$ & $\begin{array}{c}\text { Number of } \\
\text { samples }\end{array}$ & Distribution,\% \\
\hline 1 & $1,2,3,5,12$ & 5 & 38.5 \\
2.1 & 4,8 & 2 & 15.5 \\
2.2 & $11,13,10$ & 3 & 23 \\
2.3 & $6,9,7$ & 3 & 23 \\
Total & & 13 & $100 \%$ \\
\hline
\end{tabular}

The samples from the first cluster had the highest percentage of the samples-38.5\%. The wines from this group were characterized with the color intensity and hue between $1.73-1.93,0.73-0.91$ respectively. The high influence over color composition had components for $520 \mathrm{~nm}$ and the lesser influence had components for $620 \mathrm{~nm}$. The samples of the first subcluster of cluster 2 (sample 6 and 9) were character- ized by almost identical components of color content at the basic wavelengths $420 \mathrm{~nm}, 520 \mathrm{~nm}$ and 620 $\mathrm{nm}$. Samples 4 and 8 , forming the third subcluster of cluster 2 transmitted very weakly at $420 \mathrm{~nm}$ and 520 $\mathrm{nm}$ between 8 and 12\%, with hue between 0.8 and 1 , and high color intensity. For white wines a high transmission coefficient was characteristic at $420 \mathrm{~nm}$ and $520 \mathrm{~nm}$ - between $75 \%$ and $86 \%$, with maximum hue and weak color intensity - around 0.3. Hence, the second cluster grouped wines with maximum transmission and hue, and such with high color intensity and maximum absorption.

\section{CONCLUSION}

The preliminary study shows that wine can be discriminated by variety of grapes by using differences in their fluorescence spectra. We demonstrated that fluorescence measurements performed directly on the wine samples without any treatment can be used for rapid determination of vitamins, phenolic acids, flavonoids and other pigments. The quality relation between these compounds and fluorescence characteristics will be object of future investigation. Spectroscopy in the visible region gives the opportunity for quality estimation of age and variety of grapes of the wine by calculating the color characteristics hue and color intensity, respectively. The obtained results demonstrate that the color parameters are related to the content and the quality of wine.

\section{REFERENCES}

1. Kondraskov A, Sevcuk R, Benakova H, Kostirova $\mathrm{M}$, Stipek S. The key role of grape variety for antioxidant capacity of red wines. E Spen Eur E J Clin Nutr Metab. 2009; 4(1): 41-6. doi: doi.org/10.1016/j. eclnm.2008.10.004

2. Manach C, Scalbert A, Morand C, Remesy C, Jimenez L. Polyphenols: food sources and bioavailability. Am J Clin Nutr. 2004; 79(5): 727-47.

3. Fernandez-Pachyn MS, Villaco D, Garcia-Parrilla MC, Troncoso AM. Antioxidant activity of wines and relation with their polyphenolic composition. Anal Chim Acta. 2004; 513(1):113-8. doi: 10.1016/j. aca.2004.02.028v

4. Strasburg GM, Ludescher RD. Theory and applications of fluorescence spectroscopy in food research. Trends Food Sci Technol. 1995; 6(3): 69-75. doi: 10.1016/S0924-2244(00)88966-9 
Krastena Nikolova, Stefka Minkova, Tinko Eftimov et al.

5. Dufour E, Letort A, Laguet A, Lebecque A, Serra JN. Investigation of variety, typicality and vintage of French and German wines using front-face fluorescence spectroscopy. Anal Chim Acta. 2006; 563(1-2):292-9. doi: 10.1016/j.aca.2005.11.005

6. Sadecka J, Tothova J, Majek P. Classification of brandies and wine distillates using front face fluorescence spectroscopy. Food Chem. 2009; 117(3): 491-8. doi: 10.1016/j.foodchem.2009.04.053

7. Azcarate SM, de Araujo Gomes A, Alcaraz MR, Ugulino de Araujo MC, Camina JM, Goicoechea HC. Modeling excitation-emission fluorescence matrices with pattern recognition algorithms for classification of Argentine white wines according grape variety. Food Chem.2015; 184(1): 214-9. doi: 10.1016/j.foodchem.2015.03.081

8. Glories Y. Le bois et la qualit e des vins et des eauxde-vie. ed. G. Gimberteau: Special: Conn. Vigne Vin 1987.

9. Ribereau-Gayon P, Glories Y, Maujean A, Dubourdieu D. The Chemistry of Wine Stabilization and Treatments. In: Handbook of Enology, Volume 2. 2nd Edition. Bordeaux, France: Aquitaine Traduction; 2006.

10. Duran B, Odelle P. Cluster analysis. Moscow: Statistics; 1977.

11. Ward JH. Hierarchical grouping to optimize all objective functions. J Am Stat Assoc. 1963; 58(301): 236-44.

12. Airado-Rodrigez D, Galeno-Diaz T, Duran-Meraz I, Wold JP. Usefulness of fluorescence excitationemission matrices in combination with PARAFAC as fingerprints of red wines. J Agric Food Chem. 2009; 57(5): 1711-20. doi: 10.1021/jf8033623

13. Tóthová J, Žiak L, Sádecká J. Characterization and classification of distilled drinks using total luminescence and synchronous fluorescence spectroscopy. Acta Chim Slov. 2008; 1(1): 265-75.

14. Sádecká J, Tóthová J, Májek P. Classification of brandies and wine distillates using front face fluorescence spectroscopy. Food Chem. 2009; 117(3):491-8. doi: 10.1016/j.foodchem.2009.04.053

15. Caldeira I, Pereira R, Climaco MC, Belchior AP, Bruno de Sousa V. Improved method for extraction of aroma compounds in aged brandies and aqueous alcoholic wood extracts using ultrasound. Anal Chim Acta. 2004; 513:125-34. doi: 10.1016/j. aca.2003.10.011
16. Bravo MN, Silva S, Coelho AV, Vilas Boas L, Bronze MR. Analysis of phenolic compounds in Muscatel wines produced in Portugal. Anal Chim Acta. 2006; 563(1-2): 84-92. doi: 10.1016/j. aca.2005.11.054

17. Rodriguez-Delgado MA, Malovana S, Perez JP, Borges T, Garci'Montelongo FJ. Separation of phenolic compounds by high-performance liquid chromatography with absorbance and fluorimetric detection. J Chromatogr A. 2001; 912(2):249-57. doi: 10.1016/S0021-9673(01)00598-2

18. Lakowicz JR. Principles of Fluorescence Spectroscopy. Third Edition. Springer; 2006.

19. Krasnikov VV, Timoshkin EI. Luminescencija pishchevih productov. Legkaja i pishchevaija promishlenost; 1983.

20. Christensen J, Nørgaard L, Bro R, Engelsen SB. Multivariate autofluorescence of intact food systems. Chem Rev. 2006; 106:1979-1994.

21. Mycek MA. Fluorescence spectroscopy. Gl. Endoscopy. 1998 4: 390.

22. Cristensen J, Norgaard L, Bro R, Engelsen SB. Multivariate autofluorescence of intact food systems. Chemical Reviews. 2006; 106(6): 1979-94. doi: $10.1021 / \mathrm{cr} 050019 \mathrm{q}$

23. Fernandez-Sola J. Cardiovascular risks and benefits of moderate and heavy alcohol consumption. Nat Rev Cardiol. 2015; 12(10): 576-87. doi: 10.1038/ nrcardio. 2015.91

24. Lia MA. Anthocyanins and human health: in vitro investigative approach. J Biomed Biotechnol. 2004; 2004(5):306-13. doi: 10.1155/S111072430440401X

25. Chambers JC, Ueland PM, Obeid OA, Wrigley J, Refsum H, Kooner JS. Improved vascular endothelial function after oral B vitamins - an effect mediated through reduced concentrations of free plasma homocysteine. Circulation. 2000; 102:2479-83. doi: 10.1161/01.CIR.102.20.2479

26. House AA, Eliasziw M, Cattran DC, Churchill DN, Oliver MJ, Fine A, et al. Effect of B-vitamin therapy on progression of diabetic nephropathy: a randomized controlled trial. JAMA. 2010; 303(16): 1603-9. doi: 10.1001/jama.2010.490.

27. Klatsky AL, Armstrong MA. Alcoholic beverage choice and risk of coronary artery disease mortality: do red wine drinkers fare best. Am J Cardiol. 1993; 71(5): 467- 9. doi: 10.1016/0002-9149(93)90460-T 
28. Grønbæk M, Deis A, Sørensen TIA, Becker U, Schnohr P, Jensen G. Mortality associated with moderate intake of wine, beer or spirits. Br Med J. 1995; 310: 1165-9. doi: 10.1136/bmj.310.6988.1165

29. Zingg JM. Vitamin E and mast cells. Vitam Horm. 2007; 76:393-418. doi: 10.1016/ S0083-6729(07)76015-6

30. Mainardi T, Kapoor S, Bielory L. Complementary and alternative medicine: Herbs, phytochemicals and vitamins and their immunologic effects. J Allergy Clin Immunol. 2009; 2:281-94. doi: 10.1016/j. jaci.2008.12.02

31. Vinson JA, Jang J. In vitro and in vivo lipoprotein antioxidant effect of a citrus and ascorbic acid on normal and hypercholesterolemic human subject. J Med Food. 2001; 4(4): 187-92. doi: $10.1089 / 10966200152744454$

32. Kaur G, Kathariya R, Bansal Sh, Singh Ar, Shahakar D. Dietary antioxidants and their indispensable role in periodontal health. J Food Drug Anal. 2016; 24(2): 239-46. doi: 10.1016/j.jfda.2015.11.003

33. Makimura M, Hirasawa M, Kobayashi K, Indo J, Sakahana S, Taguchi T, et al. Inhibitory effect of tea catechins on collagenase activity. J Periodontol. 1993; 64(7): 630-6. doi: 10.1902/jop.1993.64.7.630

34. Delcheva M, Kemilev St, Tagareva-Delcheva S, Bakardjieva V. Extraction of phenolic compounds and polysaccharides during the vinification of Mavrud grape-Influence of the simulated and the real alcoholic fermentation. Scientific works "Food science, engineering and technologies". 2013; LX: 1490-1493.

35. Glories Y. La couleur des vins rouges (II Mesure, Origine et interpretation). J Int Sci Vigne Vin. 1984; 18(3): 253-71. doi: 10.20870/ oeno-one.1984.18.3.1751

36. Shobanova D. Oenological Practice Guide. Plovdiv: University of Food Technologies,; 2007. 